\title{
VERIFYING OF THE HYPOTHESES AS FOR EXPENSES CAUSED BY ENTERPRISES ACTIVITY INFLUENCE ON ENVIRONMENT MODELING
}

\section{Lyudmyla Bartkova, Frederick Satkowiak}

\author{
Ternopil Academy of National Economy \\ Institute of Computer Information Technologies \\ 3, Peremogy Square, Ternopil 46004, Ukraine \\ E-mail: 1b74@ukr.net
}

\begin{abstract}
How does industry effect on the environment cause health problems among the population? What levels of pollution affect the health of the population? Can the effects be measured, predicted, or controlled? Can the costs of health care be predicted based on ecological factors? Is there any correlation between the health of a population and environmental factors? The hypotheses as for the correlation between integrated ecological and social-economical factors and expenses caused by industry on environment are represented in the paper. The verifying of the hypotheses is illustrated by means of the concrete examples.
\end{abstract}

Key words: modeling, environment, disease level, interval analysis.

Modeling of the expenses caused by enterprises economic activity influence on environment is the main problem during the influence analysis. Though the idea of damages estimation is rather simple it's difficult practically to calculate the expenses $[2,5$, 6]. As rule the following kinds of influence are estimated:

1. The decrease of life quality (the increase of diseases level);

2. The decrease of estate qualities;

3. The decrease of quality of air, water, soil used in national economy.

The expenses caused by the decrease of life quality (the increase of diseases level) are considered on the papers. Since human being's health is formed by means of not only ecological factors but social ones as well, both group of factor should be taken into consideration estimation the expenses. There are a great number of social and ecological factors. To model the expenses the method of integrated factors building on the base of fuzzy sets was used [4]. The expenses caused by the increase of diseases level are not the probable values. At the same time the definite intervals of their possible meanings are known. That's why the method of interval date was used for expenses describing [3]. To build the model of expenses the following hypotheses were used:

Hypothesis 1. The correlation between ecological, social-economical factors and expenses for treatment of the $\mathrm{k}$-th class of diseases are described by means of linier-parameterized equation

$$
y_{0 k}=\vec{\varphi}_{k}^{T}\left(\vec{x}_{k}\right) \vec{\beta}_{k}
$$

where $y_{o k}$ - the meanings of monthly expenses for treatment of the k-th class of disease; $\vec{\varphi}_{k}^{T}\left(\vec{x}_{k}\right)$-the vector of known basic functions; $\vec{x}_{k}=\left(\mathrm{x}_{1 \mathrm{k}}, \mathrm{x}_{2 \mathrm{k}}\right)^{\mathrm{T}}-$ the vector whose components are meanings of integrated ecological $\mathrm{x}_{1 \mathrm{k}}$ and social-economic $\mathrm{x}_{2 \mathrm{k}}$ factors; $\vec{\beta}_{k}$-the vector of unknowing parameters of the model.

Hypothesis 2. The estimation $\vec{b}_{k}$ of the vector of unknowing parameters $\vec{\beta}_{k}$ are obtained on the base of the date getting as a result of conducting passive experiment:

$$
\mathrm{X}_{\mathrm{k}} \rightarrow\left[\vec{y}_{k}\right],
$$

where $\mathrm{X}_{\mathrm{k}}=\left(\vec{x}_{1 k}, \ldots, \vec{x}_{n k}\right)^{\mathrm{T}}-$ the matrix whose components are the meanings of ecological and social factors in the social-ecological zones (the districts with certain social-economic and ecological conditions $), \quad \vec{x}_{i k}=\left(\mathrm{x}_{\mathrm{ilk}}, \mathrm{x}_{\mathrm{i} 2 \mathrm{k}}\right)^{\mathrm{T}}$-the vector of the meaning of integrated ecological $x_{i 1 k}$ and socialeconomic $\mathrm{x}_{\mathrm{i} 2 \mathrm{k}}$ factors on the $\mathrm{i}$-th social-ecological 
zone (SEZ) for the $\mathrm{k}$-th class of diseases; $\mathrm{x}_{\mathrm{ijk}} \in 0, \ldots, 1$. The bigger is $\mathrm{x}_{\mathrm{ijk}}$, the more correspondent conditions is "Satisfied"; $\left[\vec{y}_{k}\right]=\left(\left[\mathrm{y}_{1 \mathrm{k}}\right], \ldots,\left[\mathrm{y}_{\mathrm{ik}}\right], \ldots, .\left[\mathrm{y}_{\mathrm{n} 11}\right]\right)^{\mathrm{T}}-$ the vector of interval meanings of expenses in the I-th socialecological zone for the $\mathrm{k}$-th class of diseases;

Hypothesis 3. The true meaning of the expenses in the I-th social-ecological zone $y_{0 k}=\vec{\varphi}_{k}^{T}\left(\vec{x}_{k}\right) \vec{\beta}_{k}$, is in the known interval $\left[y_{i k}\right]=\left[y_{i k}^{-}, y_{i k}^{+}\right]$, i.e. $y_{i k}^{-} \leq y_{0 k} \leq y_{i k}^{+}$.

Taking into consideration hypothesis 1-3 the estimation $\vec{b}_{k}$ of the vector $\vec{\beta}_{k}$ must satisfy the system of inequalities

$$
y_{i k}^{-} \leq \vec{\varphi}_{k}^{T}\left(\vec{x}_{k}\right) \vec{b}_{k} \leq y_{i k}^{+}, \quad \forall \mathrm{i}=1, \ldots, \mathrm{n} .
$$

If the solution of the system (1) exists then

$$
\left[y_{k}\left(\vec{x}_{k}\right)\right]=\left[y_{k}^{-}\left(\vec{x}_{k}\right), y_{k}^{+}\left(\vec{x}_{k}\right)\right],
$$

where $y_{k}^{-}\left(\vec{x}_{k}\right)=\min _{\vec{b}_{k j} \in \Omega} \vec{\varphi}_{k}^{T}\left(\vec{x}_{k}\right) \vec{b}_{k}^{-} ; y_{k}^{+}\left(\vec{x}_{k}\right)=\max _{\vec{b}_{k j} \in \Omega}$ $\vec{\varphi}_{k}^{T}\left(\vec{x}_{k}\right) \vec{b}_{k}^{+}$is the model of correlation between the ecological and social-economical factors and expenses.

The i-th inequality in the system (2) means passing the model (3) in the I-th interval meaning $\left[y_{i k}\right]$. Incompatibility of the system (2) means abnormality of the hypotheses, i.e. abnormality of the kind of the function (1), or abnormality of the interval meanings $\left[y_{i k}^{-}, y_{i k}^{+}\right]$, i.e. impossibility to pass the function through the all intervals [ ].

In case when the system (2) is compatible, the set of its solutions $\Omega=\left\{\vec{b}_{л 3}: y_{i k}^{-} \leq \vec{\varphi}_{k}^{T}\left(\vec{x}_{k}\right) \vec{b}_{л 3} \leq y_{i k}^{+} \quad \forall \mathrm{i}\right.$ $=1, \ldots, \mathrm{n}\}$ is the convex multisided in the space $R^{m}$. Thus $\mathrm{p}$ is the number of the top of the $\Omega$. The true unknowing vector $\vec{\beta}_{k}$ is one of the solutions of the system (2.2), i.e. $\vec{\beta}_{k} \in \Omega$.

The main attention is paid to the chose of the structure of the model of correlation between the integrated ecological and social-economic factors and expenses. It's proved [3] that in the interval analysis the more simple the model is (with the least number of the coefficients and the simplest structure the more accurate it is. One of the following conditions must be executed to optimize the structure of the model: minimization of the polynomial power; minimization of the quantity of the entrance variables; minimization of the quantity of the coefficients.

To find out the optimal structure of the polynomial the following methods may be used: the method of complete sorting; the method of consecutive including; the method of consecutive excluding. Using the method of complete sorting all possible polynomials limited with the definite quantity of entrance variables and the power are formed. Each polynomial is put into the system (2). The polynomial satisfied all of the inequalities of the system are allocated. The required polynomial is the polynomial of the simplest structure. The methods based on the consecutive including or excluding of the coefficients are more economic in comparison with the method of complete sorting. The consecutive complication of the structure of the polynomial is the base of the method of consecutive including. If the polynomial satisfies the inequality (2) the complication is finished. In the method of consecutive excluding the possible simplifications of the polynomial are investigated.

To find out the optimal structure of the polynomial it's easier to use its approached description of the rectangular hyper prism $\Pi^{+}=\left\{\vec{b}_{k p} \in R^{m} \mid b_{k j}^{-} \leq b_{k j} \leq b_{k j}^{+}, \mathrm{j}=1, \ldots, \mathrm{m}\right\}$ instead of the region $\Omega$.

The extreme points $b_{k j}^{-}, \quad b_{k j}^{+}$may be calculated by means of the solving $2 \mathrm{~m}$ problems of the linier programming:

$$
\begin{aligned}
b_{k j}^{-}=\min _{\bar{b}_{k p} \in \Omega} & b_{k j p} ; \\
& b_{k j}^{+}=\max _{\bar{b}_{k p} \in \Omega} b_{k j p} .
\end{aligned}
$$

If $\operatorname{sing} b_{k j}^{-}=\operatorname{sing} b_{k j}^{+}$all coefficients $\vec{b}_{k}$ of the model (3) are meaningful. If $\operatorname{sing} b_{k j}^{-} \neq \operatorname{sing} b_{k j}^{+}$then the $\mathrm{j}$-th coefficient may be excluded.

The described approaches are effective enough to find out the optimal structure of the model (3) on the base of the interval date analysis.

To verify the hypotheses as for the correlation between integrated ecological and social-economical factors and expenses caused by enterprises activity influence on environment, the passive experiment for four typical social-ecological zones was hold [1].

The monthly expenses $\left[\mathrm{y}_{\mathrm{ik}}\right]$ for four socialecological zones are represented in the table 1.

The meanings of the integrated social-economical $\mathrm{x}_{\mathrm{i} 23}$ and ecological $\mathrm{x}_{\mathrm{i} 13}$ factors for the diseases of the breath organs calculated according the method described in [1] is represented in the table 2. 
By means of the method of consecutive including the structure of the model of expenses for breath organs diseases treatment was built:

$$
\left[y_{3}\left(\vec{x}_{3}\right)\right]=\left[y_{3}^{-}\left(\vec{x}_{3}\right), y_{3}^{+}\left(\vec{x}_{3}\right)\right] \text {, }
$$

where

$$
y_{3}^{-}\left(\vec{x}_{3}\right)=\min _{b_{3} p \in \Omega}\left(\mathrm{b}_{03 \mathrm{p}}\right.
$$$$
\left.+\quad b_{13 \mathrm{p}} \mathrm{x}_{13} \mathrm{x}_{23}\right)
$$

$y_{3}^{+}\left(\vec{x}_{3}\right)=\max _{\vec{b} 3 p \in \Omega}\left(\mathrm{b}_{03 \mathrm{p}}+\mathrm{b}_{13 \mathrm{p}} \mathrm{x}_{13} \mathrm{x}_{23}\right)$.

The meanings of the coefficients $\vec{b}_{3 p}$, are represented in the table 3 .

Table 1. Monthly expenses

\begin{tabular}{|l|c|c|c|c|}
\hline \multirow{2}{*}{$\begin{array}{l}\text { The name of the k-th } \\
\text { class of diseases }\end{array}$} & \multicolumn{4}{|c|}{ The expenses for treatment, UAH for 1000 people } \\
\cline { 2 - 5 } & {$\left[\mathrm{y}_{1 \mathrm{k}}\right]$} & \multicolumn{4}{|c|}{$\left[\mathrm{y}_{2 \mathrm{k}}\right]$} & {$\left[\mathrm{y}_{\mathrm{ik}}\right]$} & {$\left[\mathrm{y}_{4 \mathrm{k}}\right]$} \\
\hline $\begin{array}{l}\text { The diseases of the } \\
\text { nerve system }\end{array}$ & {$[710.4,717.5]$} & {$[700.8,707.8]$} & {$[696,702.96]$} & {$[686.4,693.3]$} \\
\hline $\begin{array}{l}\text { The diseases of the } \\
\text { circulation of the blood }\end{array}$ & {$[472.5,477.2]$} & {$[461.3,465.9]$} & {$[450,454.5]$} & {$[438.8,443.1]$} \\
\hline $\begin{array}{l}\text { The diseases of the } \\
\text { breath organs }\end{array}$ & {$[735.8,743.16]$} & {$[730.6,737.9]$} & {$[717.6,724.8]$} & {$[712.4,719.5]$} \\
\hline $\begin{array}{l}\text { The diseases of the } \\
\text { digestion system }\end{array}$ & {$[619.75,625.9]$} & {$[603.5,609.5]$} & {$[591.3,597.2]$} & {$[583.2,589]$} \\
\hline $\begin{array}{l}\text { The diseases of the } \\
\text { bones and muscle } \\
\text { system }\end{array}$ & {$[436.2,440.6]$} & {$[423.1,427.4]$} & {$[410,414.1]$} & {$[393.6,397.5]$} \\
\hline New growths & {$[346.8,350.3]$} & {$[337.3,340.7]$} & {$[332.5,335.9]$} & {$[327.8,331.1]$} \\
\hline $\begin{array}{l}\text { The diseases of blood } \\
\text { and blood making } \\
\text { organs }\end{array}$ & {$[301.9,304.9]$} & {$[295.9,298.9]$} & {$[292.8,295.7]$} & {$[289.8,292.7]$} \\
\hline $\begin{array}{l}\text { The diseases of the } \\
\text { endocrine system }\end{array}$ & {$[408.3,412.4]$} & {$[401.2,405.2]$} & {$[397.6,401.6]$} & {$[394.1,398.1]$} \\
\hline
\end{tabular}

Table 2. The meanings of the integrated social-economical $x_{i 23}$ and ecological $x_{i 13}$ factors for the diseases of the breath organs

\begin{tabular}{|c|c|c|c|}
\hline I & Social-ecological zone & $\mathrm{X}_{\mathrm{i} 13}$ & $\mathrm{X}_{\mathrm{i} 23}$ \\
\hline 1 & & 0.344 & 0.185 \\
& SEZ1 & & \\
\hline 2 & SEZ2 & 0.365 & 0.204 \\
\hline 3 & SEZ3 & 0.417 & 0.214 \\
\hline 4 & SEZ4 & 0.440 & 0.234 \\
\hline
\end{tabular}

Table 3. The meaning of the coefficients $\vec{b}_{3 p}$

\begin{tabular}{|c|c|c|c|c|c|}
\hline $\mathrm{p}$ & 1 & 2 & 3 & 4 & 5 \\
\hline $\mathrm{b}_{03}$ & 765.780 & 788.827 & 763.189 & 793.201 & 779.009 \\
\hline $\mathrm{b}_{13}$ & -471.516 & -718.288 & -430.769 & -787.075 & -648.827 \\
\hline
\end{tabular}

$b_{03}^{-}=763.189, b_{03}^{+}=793.201, b_{13}^{-}=-787.075, b_{13}^{+}=-$ 430.769. Since sing $b_{03}^{-}=\operatorname{sing} b_{03}^{+}$and $\operatorname{sing} b_{13}^{-}=\operatorname{sing}$ $b_{13}^{+}$, then the coefficients $b_{03}$ and $b_{13}$ are meaningful. To check the adequacy of the model (4) the comparison of the real interval meanings $\left[\mathrm{y}_{\mathrm{i} 3}\right]$ iand 
predicted ones $\left[y_{i 3}\right]$ was hold. If $\mathrm{x}_{113}=0.344$, $\mathrm{x}_{123}=0.185$ then $\left[\mathrm{y}_{23}\left(\mathrm{x}_{113}, \mathrm{x}_{123}\right)\right]=[735.8,743.16]$, $\left[y_{i 3}\left(\mathrm{x}_{113}, \mathrm{x}_{123}\right)\right]=[735.8,743.16]$. If $\mathrm{x}_{213}=0.365$, $\mathrm{x}_{223}==0.204$, then $\left[\mathrm{y}_{23}\left(\mathrm{x}_{213}, \mathrm{x}_{223}\right)\right]=[730.6,737.9]$, $\left[f_{23}\left(\mathrm{x}_{213}, \mathrm{x}_{223}\right)\right]=[730.6,737.9]$. If $\mathrm{x}_{313}=0.417, \mathrm{x}_{323}=$ 0.214 then $\left[\mathrm{y}_{33}\left(\mathrm{x}_{313}, \mathrm{x}_{323}\right)\right]=[717.6,724.8],\left[f_{33}\left(\mathrm{x}_{313}\right.\right.$, $\left.\left.\mathrm{x}_{323}\right)\right]=[717.6,724.8]$. If $\mathrm{x}_{413}=0.440, \mathrm{x}_{423}=0.234$ then $\left[\mathrm{y}_{43}\left(\mathrm{x}_{413}, \mathrm{x}_{423}\right)\right]=[712.4,719.5],\left[y_{43}\left(\mathrm{x}_{413}, \mathrm{x}_{423}\right)\right]=$ $[712.4,719.5]$. Since the calculated meanings of the expenses pass through the all intervals of the experiment (see table 1) the model (4) is adequate.

The meanings of the integrated social-economical $\mathrm{x}_{\mathrm{i} 26}$ and ecological $\mathrm{x}_{\mathrm{i} 16}$ factors for the new growths calculated according the method described in [1] is represented in the table 4.

Table 4. The meanings of the integrated social-economical $x_{i 26}$ and ecological $x_{i 16}$ factors for the new growths

\begin{tabular}{|c|c|c|c|}
\hline $\mathrm{I}$ & Social-ecological zone & $\mathrm{X}_{\mathrm{i} 16}$ & $\mathrm{X}_{\mathrm{i} 26}$ \\
\hline 1 & $\mathrm{SEZ1}$ & 0.341 & 0.183 \\
& SEZ2 & & \\
\hline 2 & SEZ3 & 0.382 & 0.203 \\
\hline 3 & SEZ4 & 0.412 & 0.212 \\
\hline 4 & \multicolumn{2}{|c|}{0.433} & 0.232 \\
\hline
\end{tabular}

By means of the method of consecutive including the structure of the model of expenses for new growths treatment was built:

$$
\left[y_{6}\left(\vec{x}_{6}\right)\right]=\left[y_{6}^{-}\left(\vec{x}_{6}\right), y_{6}^{+}\left(\vec{x}_{6}\right)\right] \text {, }
$$

where $\quad y_{6}^{-}\left(\vec{x}_{6}\right)=\min _{\vec{b} 6 p \in \Omega}\left(\mathrm{b}_{06 \mathrm{p}}+\mathrm{b}_{16 \mathrm{p}} \mathrm{x}_{16} \mathrm{x}_{26}\right)$; $y_{6}^{+}\left(\vec{x}_{6}\right)=\max _{\vec{b} 6 p \in \Omega}\left(\mathrm{b}_{06 \mathrm{p}}+\mathrm{b}_{16 \mathrm{p}} \mathrm{x}_{16} \mathrm{x}_{26}\right)$.

The meanings of the coefficients $\vec{b}_{6 p}$ are represented in the table 5 .

Table 5. The meanings of the coefficients $\vec{b}_{6 p}$

\begin{tabular}{|c|c|c|c|}
\hline $\mathrm{P}$ & 1 & 2 & 3 \\
\hline $\mathrm{b}_{06}$ & 374.106 & 378.238 & 383.929 \\
\hline $\mathrm{b}_{16}$ & -437.033 & -503.037 & -559.741 \\
\hline
\end{tabular}

$b_{06}^{-}=374.106, b_{06}^{+}=383.929, b_{16}^{-}=-559.741, b_{16}^{+}=-$ 437.033. Since sing $b_{06}^{-}=\operatorname{sing} b_{06}^{+}$and sing $b_{16}^{-}=\operatorname{sing}$ $b_{16}^{+}$then the coefficients $b_{06}$ and $b_{16}$ are meaningful. To check the adequacy of the model (5) the comparison of the real interval meanings $\left[\mathrm{y}_{\mathrm{i}}\right]$ and the predicted ones $\left[y_{i 6}\right]$ was hold. If $\mathrm{x}_{116}=0.341$, $\mathrm{x}_{126}=0.183$ then $\left[\mathrm{y}_{26}\left(\mathrm{x}_{116}, \mathrm{x}_{126}\right)\right]=[346.75,350.254]$, $\left[y_{i 6}\left(\mathrm{x}_{116}, \mathrm{x}_{126}\right)\right]=[346.75,350.254]$. If $\mathrm{x}_{216}=0.382$, $\mathrm{x}_{226}=0.203$ then $\left[\mathrm{y}_{26}\left(\mathrm{x}_{216}, \mathrm{x}_{226}\right)\right]=[337.25,340.66]$, $\left[y_{26}\left(\mathrm{x}_{216}, \mathrm{x}_{226}\right)\right]=[337.25,340.66]$. If $\mathrm{x}_{316}=0.412$, $\mathrm{x}_{326}=0.212$ then $\left[\mathrm{y}_{36}\left(\mathrm{x}_{316}, \mathrm{x}_{326}\right)\right]=[332.5,335.86]$, $\left[y_{36}\left(\mathrm{x}_{316}, \mathrm{x}_{326}\right)\right]=[332.5,335.86]$. If $\mathrm{x}_{416}=0.433$, $\mathrm{x}_{426}=0.232$ then $\left[\mathrm{y}_{46}\left(\mathrm{x}_{416}, \mathrm{x}_{426}\right)\right]=[327.75,331.062]$, $\left[y_{46}\left(\mathrm{x}_{416}, \mathrm{x}_{426}\right)\right]=[327.75,331.062]$. Since the calculated meanings of the expenses pass through the all intervals of the experiment (table 1) the model (5) is adequate.

The meanings of the integrated social-economical $\mathrm{x}_{\mathrm{i} 27}$ and ecological $\mathrm{x}_{\mathrm{i} 17}$ factors for the blood diseases calculated according the method described in [1] is represented in the table 6 .

Table 6. The meanings of the integrated social-economical $x_{i 27}$ and ecological $x_{i 17}$ factors for the blood diseases

\begin{tabular}{|c|c|c|c|}
\hline $\mathrm{I}$ & Social-ecological zone & $\mathrm{X}_{\mathrm{i} 17}$ & $\mathrm{X}_{\mathrm{i} 27}$ \\
\hline 1 & $\mathrm{SEZ1}$ & 0.341 & 0.183 \\
& SEZ2 & & \\
\hline 2 & SEZ3 & 0.381 & 0.203 \\
\hline 3 & SEZ4 & 0.412 & 0.212 \\
\hline 4 & & 0.433 & 0.232 \\
\hline
\end{tabular}


By means of the method of consecutive including the structure of the model of expenses for blood diseases treatment was built:

$$
\left[y_{7}\left(\vec{x}_{7}\right)\right]=\left[y_{7}^{-}\left(\vec{x}_{7}\right), y_{7}^{+}\left(\vec{x}_{7}\right)\right] \text {, }
$$

where $\quad y_{7}^{-}\left(\vec{x}_{7}\right)=\min _{\vec{b} 7 p \in \Omega}\left(\mathrm{b}_{07 \mathrm{p}}+\mathrm{b}_{17 \mathrm{p}} \mathrm{x}_{17} \mathrm{x}_{27}\right)$; $y_{7}^{+}\left(\vec{x}_{7}\right)=\max _{\vec{b} 7 p \in \Omega}\left(\mathrm{b}_{07 \mathrm{p}}+\mathrm{b}_{17 \mathrm{p}} \mathrm{x}_{17} \mathrm{x}_{27}\right)$.

The meanings of the coefficients $\vec{b}_{7}$ determining the tops of the region $\Omega$ (p-the number of the top) are represented in the table 7 .

Table 7. The meanings of the coefficients $\vec{b}_{7}$

\begin{tabular}{|c|c|c|c|c|}
\hline $\mathrm{P}$ & 1 & 2 & 3 & 4 \\
\hline $\mathrm{b}_{07}$ & 317.529 & 322.169 & 322.211 & 329.280 \\
\hline $\mathrm{b}_{17}$ & -248.829 & -322.924 & -302.263 & -393.762 \\
\hline
\end{tabular}

$$
b_{07}^{-}=317.529, b_{07}^{+}=329.280, b_{17}^{-}=-393.762, b_{17}^{+}=-
$$

248.829. OSince sing $b_{07}^{-}=\operatorname{sing} b_{07}^{+}$and sing $b_{17}^{-}=\operatorname{sing} b_{17}^{+}$, then the coefficients $b_{07}$ and $b_{17}$ are meaningful. To check the adequacy of the model (3.7) the comparison of the real interval meanings $\left[\mathrm{y}_{\mathrm{i} 7}\right]$ and predicted ones $\left[y_{i 7}\right]$ was hold. If $\mathrm{x}_{117}=0.341, \mathrm{x}_{127}=0.183$ then $\left[\mathrm{y}_{27}\left(\mathrm{x}_{117}, \mathrm{x}_{127}\right)\right]=[301.95$, 304.97], $\left[\begin{array}{lll}y_{i 7} & \left(\mathrm{x}_{117}, \mathrm{x}_{127}\right)\end{array}\right]=[301.95,304.97]$. If $\mathrm{x}_{217}=0.381, \mathrm{x}_{227}=0.203$, then $\left[\mathrm{y}_{27}\left(\mathrm{x}_{217}, \mathrm{x}_{227}\right)\right]=[295.9$, $298.81],\left[y_{27}\left(\mathrm{x}_{217}, \mathrm{x}_{227}\right)\right]=[295.9,298.81]$. If $\mathrm{x}_{317}=$ $0.412, \mathrm{x}_{327}=0.212$ then $\left[\mathrm{y}_{37}\left(\mathrm{x}_{317}, \mathrm{x}_{327}\right)\right]=[292.8$, 295.73], $\left[y_{37}\left(\mathrm{x}_{317}, \mathrm{x}_{327}\right)\right]=[292.8,295.73]$. If $\mathrm{x}_{417}=$ $0.433, \mathrm{x}_{427}=0.232$ then $\left[\mathrm{y}_{47}\left(\mathrm{x}_{417}, \mathrm{x}_{427}\right)\right]=[289.75$, 292.65], $\left[y_{47}\left(\mathrm{x}_{417}, \mathrm{x}_{427}\right)\right]=[289.75,292.65]$. Since the calculated meanings of the expenses pass through the all intervals of the experiment (table 1) the model (6) is adequate.

The considered approach as for the Verifying of the hypotheses as for the correlation between integrated ecological and social-economical factors and expenses caused by enterprises activity influence on environment was used during the state ecological examination of the projects of maximum admissible throws for the range of enterprises. The models of expense on eight classes of diseases have been built during the examination.

\section{References}

1. L. Bartkowa, H. Hladij, M.Dywak, R.Kogut. Badanie $i$ regulacjia kompleksovego wplywu gospodarczej dzialalnosci przedsiebiorsyw na sdorowisko socjoekologiczne // 5 Krajowa Konferencja "Modelowanie Cybernetyczne Systemow Biologicznych”.- Krakow, 2000.- s. 139-141.

2. Baumol W.J., Oates W. The Theory of Environmental Policy: Externalities, Public Outlays and the Quality of life. Prentice Hall. New Jerscy, 1975, $123 p$.

3. Design of experiments and data analysis: new trends and results / Edited by Prof. Letzky E.K.Moscow.- 1993.- 192 p.

4. R. Kogut, O. Lytvynova, S. Tsepeniuk, L. Bartkova, O. Kramar Working up of technology of medical and ecological conditions modeling for sanitary-epidemiological unit of Ternopil // Papers of the second International meeting "Applying the anthropocentric approach".Krakow, 1996.-p.7-8.

5. Park C.C. Ecolgy and environmental management.- Folk-stone, 1980.- 300 p.

6. Pearce D., Turner K. Economics of Natural Resources and the Environment. N.Y., 1990.$146 \mathrm{p}$.

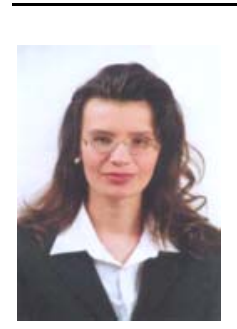

Lyudmyla M. Bartkova is a lecture of Economical Systems and Processes Modeling and Optimization Department (Ternopil Academy of National Economy). In 1996 she graduated the Institute of Computer Information Technologies TANE, majorInformation Systems in Management. In 1999 she graduated post-graduate Department TANE on Economical-Mathematical Modeling. The subject of researches is Economicalmathematical Modeling of economical activities influence on social-ecological environment results.

Frederick Satkowiak. B.S., O.D. Bachelor of Science, Mathematical Science, United States Military Academy, West Point, New York. Doctor of Optometry, Indiana University, Bloomington, Indiana. Interests.

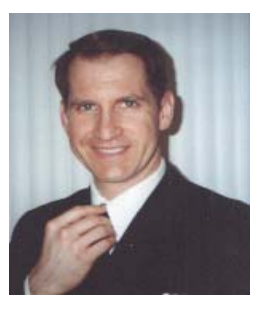
Study vision and human perception. Enjoys crossword puzzles, cooking, partner dancing, and music. 